\title{
Enfermedad renal por depósito idiopático de cadenas livianas. Caso clínico
}

\author{
HERNÁN TRIMARCHI ${ }^{1}$, FERNANDO LOMBI ${ }^{1}$, MARIANO FORRESTER ${ }^{1}$, \\ VANESA POMERANZ ${ }^{1}$, OSCAR RABINOVICH ${ }^{3}$, GERMÁN R. STEMMELIN ${ }^{3}$, \\ PABLO A. RUIZ ${ }^{2}$, ALEJANDRO IOTTI ${ }^{4}$, PABLO YOUNG ${ }^{2}$
}

Servicios de ${ }^{1}$ Nefrología, ${ }^{2}$ Clínica Médica, ${ }^{3}$ Hematología y ${ }^{4}$ Anatomía Patológica, Hospital Británico de Buenos Aires, Argentina.

Recibido el 30 de octubre de 2011, aceptado el 8 de octubre de 2012

Correspondencia a: Dr. Pablo Young, Hospital Británico. Perdriel 74 (1280) Buenos Aires, Argentina.

Tel: 541143096400

Fax: 541143043393

E-mail: pabloyoung2003@ yahoo.com.ar

\section{Kidney involvement in idiopathic light chain disease. Report of one case}

\begin{abstract}
Idiopathic Light Chain disease (ILCD) is a systemic disease characterized by a deposit in different organs of light chain monoclonal immunoglobulins, produced by an abnormal clone of $B$ cells. It is usually found in the course of a plasma cell dyscrasia and in other lymphoproliferative alterations; however it may occur in absence of any hematologic disease and is denominated as idiopathic. We report a 51-year-old male admitted to the hospital due to anasarca. Laboratory evaluation showed a serum creatinine of $1.4 \mathrm{mg} / \mathrm{dl}$, a serum albumin of $1.6 \mathrm{~g} / \mathrm{dl}$, a serum cholesterol of $687 \mathrm{mg} / \mathrm{dl}$ and a proteinuria of $5.3 \mathrm{~g} /$ day. Light chains with a predominance of a monoclonal component were identified in urinary proteins by electrophoresis and kappa chains were identified by immunofixation. A renal biopsy showed a diffuse nodular glomerulopathy with a 35\% tubular atrophy and interstitial sclerosis. Electron microscopy confirmed light chain deposition. The bone marrow biopsy showed a myeloid hyperplasia. The patient was initially treated with methylprednisolone and plasmapheresis with a reduction in serum creatinine and disappearance of urinary kappa component. Albuminuria persisted and a malnutrition-inflammatory complex syndrome was diagnosed. Hemodialysis with ultrafiltration was started along with cyclophosphamide. The patient received hemodialysis for six months and continued with methylprednisolone.
\end{abstract}

(Rev Med Chile 2013; 141: 396-401).

Key words: Immunoglobulin Light chains; Proteinuria; Plasmapheresis; Renal dialysis.
$\mathrm{L}$ a enfermedad por cadenas livianas (ECL) es una enfermedad sistémica caracterizada por el depósito de cadenas livianas de inmunoglobulinas monoclonales en varios órganos producidos por un clon anormal de células B. Antonovych describió las cadenas livianas monoclonales el año 1973 y la enfermedad por depósito de cadenas livianas fue confirmada por Randall y col en $1976^{1}$. Se suele encontrar en el curso de una discrasia de células plasmáticas, en otros trastornos linfoproliferativos, sin embargo, puede ocurrir en ausencia de cualquier trastorno hematológico, denominándose idiopática ${ }^{1}$. La ECL se encuentra en $5 \%$ de los pacientes con mieloma. En una serie de 7.241 biopsias renales se hallaron 12 casos de cadenas livianas lo que representa $0,33 \%$ en un período de 18 años 2 . El rango de edad va de 26 a 94 años, con una media de 57 años y predomina en sexo masculino ${ }^{1,2}$. Presentamos un caso internado en el Hospital Británico con ECL, y una revisión de la literatura con el objetivo de ilustrar a los internistas sobre esta patología de baja frecuencia.

\section{Caso clínico}

Paciente de sexo masculino, de 51 años de edad, internado debido a un cuadro de anasarca crónica. Al examen físico no mostró otros hallazgos de relevancia como linfadenopatías u 
Enfermedad por cadenas livianas - $\mathrm{H}$. Trimarchi et al

organomegalias. Peso corporal: $90 \mathrm{~kg}$, presión arterial $110 / 70 \mathrm{mmHg}$, diuresis conservada. Laboratorio: hematocrito 36\%, leucocitos 6.500 $\mathrm{mm}^{3}$, velocidad de eritrosedimentación globular (VSG) $120 \mathrm{~mm}$ en $1 \mathrm{~h}$ (normal < 20), creatinina $1,4 \mathrm{mg} / \mathrm{dl}$ (clearence de creatinina medido: 69 $\mathrm{ml} / \mathrm{min}$ ), albúmina $1,6 \mathrm{~g} / \mathrm{dl}$, sodio $128 \mathrm{mEq} / \mathrm{L}$, potasio $3,9 \mathrm{mEq} / \mathrm{L}$, calcio $7,1 \mathrm{mg} / \mathrm{dl}$, colesterol $687 \mathrm{mg} / \mathrm{dl}$, proteinuria 5,3 g/día. Se identificaron cadenas livianas con predominio de componente monoclonal mediante uroproteinograma electroforético y cadenas kappa por inmunofijación, con resultados negativos en sangre periférica. Serología de HBV, HCV, HIV, anticuerpos antinucleares y anticuerpos anti-citoplasma de neutrófilos negativos. Niveles de complemento normales. Criocrito $<1 \%$. Ecocardiograma Doppler: normal. La biopsia renal reveló una glomerulopatía nodular difusa con 35\% de atrofia tubular y esclerosis intersticial (Figura 1), con tinción de rojo Congo negativa, la morfología de la microscopia de luz se semeja a la glomeruloesclerosis de Kimmelstiel Wilson de la diabetes mellitus. La inmunofluorescencia fue positiva para las cadenas kappa (Figura 2) y la microscopia electrónica confirmó la existencia de depósitos de cadenas livianas, no existiendo elementos que hicieran pensar en amiloide, crioglobulinas, tactoide u otras fibrillas también relacionadas a trastornos clonales de linfocitosplasmocitos (Figura 3). Biopsia de médula ósea: hiperplasia mieloide.

El paciente evolucionó con incremento de la creatinina a $2,2 \mathrm{mg} / \mathrm{dl}$, iniciando tratamiento con meprednisona $0,5 \mathrm{mg} / \mathrm{kg}$ y plasmaféresis. Después de diez sesiones consecutivas, y con albúmina como reposición, la albuminemia se elevó a 3,1 $\mathrm{g} / \mathrm{dl}$, la creatinina disminuyó a $1,5 \mathrm{mg} / \mathrm{dl}$ y el componente monoclonal kappa urinario prácticamente desapareció, pero la albuminuria se elevó a $80 \mathrm{~g} /$ día, posiblemente debido a la albúmina de reposición, aunque el motivo de este incremento no quedó del todo claro. Inició tratamiento con pulsos mensuales de ciclofosfamida $1 \mathrm{~g} / \mathrm{iv}$ con una proyección de seis aplicaciones. El paciente tuvo un MIS (score de malnutrición e inflamación) de 26 (rango de 0 a 30) lo que implica malnutrición grave, sumado a la elevación de marcadores inflamatorios, con la VSG que se mencionó previamente y una proteína $C$ reactiva (PCR) $3,7 \mathrm{mg} /$ dl (normal $<0,3)$. A pesar que los marcadores inflamatorios elevados podrían deberse a la pato-

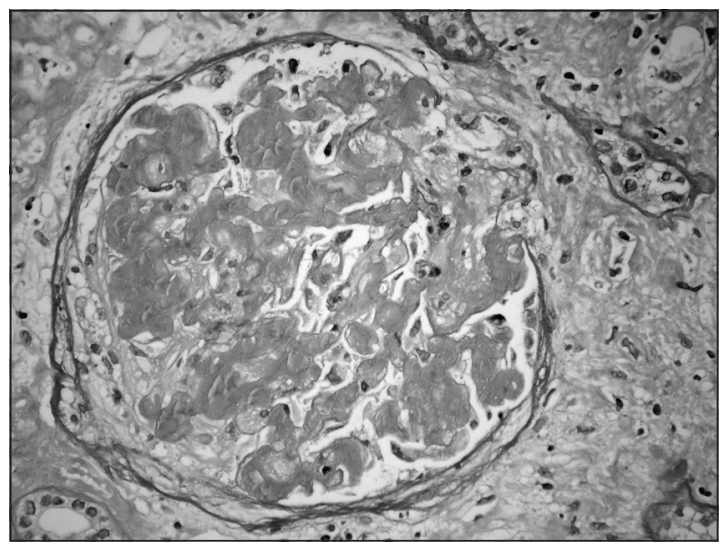

Figura 1. Glomeruloesclerosis nodular. Microscopia óptica, PAS 400X.

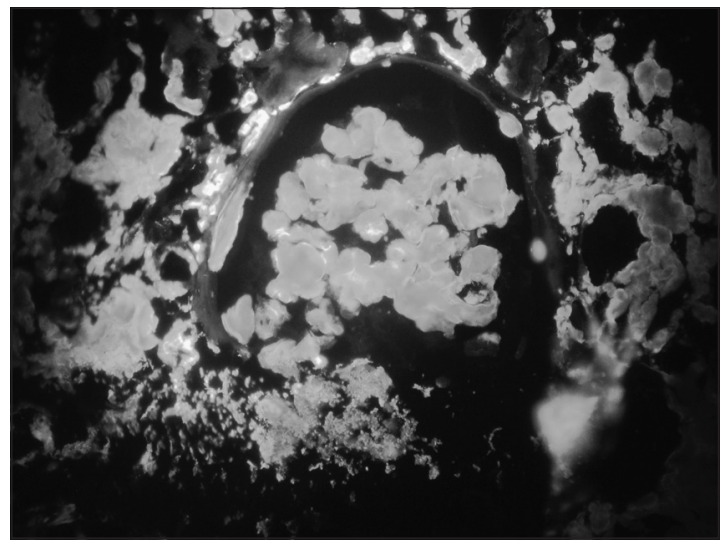

Figura 2. Intensa inmunofluorescencia positiva para cadenas livianas Kappa en glomérulo, túbulos y membranas basales vasculares 400X.

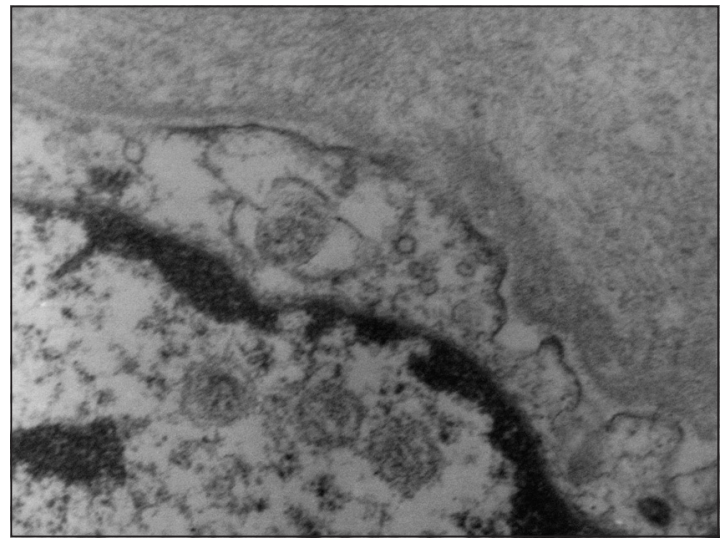

Figura 3. Depósito electrón denso puntiforme a lo largo de la membrana basal tubular. 36000X. 
logía de base y la hipoalbuminemia es atribuible principalmente al síndrome nefrótico, se realizó diagnóstico de MICS (malnutrition-inflammatory complex syndrome) secundario a síndrome nefrótico por enfermedad de cadenas livianas, y comenzó hemodiálisis con ultrafiltración diaria a pesar de los niveles casi normales de creatinina. Se prescribió dieta hipercalórica (35 calorías/kg/ día). Su estado clínico mejoró, objetivándose una pérdida de $23 \mathrm{~kg}$ de peso corporal, sin edemas y una mejoría significativa del estado nutricional. La creatinina disminuyó a 1,6 mg/dl (cleareance de creatinina medido: $52 \mathrm{ml} / \mathrm{min}$ ). Después de la tercera infusión mensual de ciclofosfamida el componente monoclonal de la cadena kappa urinaria desapareció por completo, sin presentar componente monoclonal en sangre. Se empleó enalapril, furosemida y dosis bajas de indometacina con el fin de lograr una nefrectomía química y reducir la proteinuria masiva con aceptables resultados. Esta última disminuyó gradualmente a niveles promedio de $7 \mathrm{~g} /$ día en 1 litro de diuresis diaria y la albuminemia se elevó a 2,6 g/dl. El paciente continuó con hemodiálisis por un período de seis meses, y continuó recibiendo meprednisona $10 \mathrm{mg} /$ día.

\section{Discusión}

La enfermedad por cadenas livianas se caracteriza por ser una enfermedad sistémica con depósito de cadenas livianas de inmunoglobulinas monoclonales en varios órganos producidos por un clon anormal de células $\mathrm{B}^{1}$. Los órganos frecuentemente comprometidos son corazón (cardiomiopatía restrictiva, infarto de miocardio), hígado (ictericia colestásica, insuficiencia hepática), cerebro (infarto y/o hemorragia cerebral), sistema nervioso periférico (neuropatía periférica y mononeuritis múltiple), pulmón, riñón y músculo entre otros ${ }^{2,3}$. Esta alteración se puede encontrar en el curso de una discrasia de células plasmáticas (mieloma múltiple), 50\% de los pacientes, en trastornos linfoproliferativos o como se informa en nuestro paciente, en ausencia de cualquier trastorno hematológico denominándose idiopática, entre otros cuadros (Tabla 1).

En el presente caso la paraproteína monoclonal sólo se encontró en la orina. Esto está en consonancia con las observaciones que afirman que la afinidad a los tejidos de las cadenas livianas es más importante que sus niveles circulantes para determinar su depósito y su nivel de injuria ${ }^{3,4}$. Por otra parte, durante la hipoalbuminemia severa, la técnica de electroforesis puede llevar a resultados confusos, según algunos autores, en la identificación de pequeñas cantidades de cadenas livianas ${ }^{1-5}$. En un estudio retrospectivo de 63 pacientes con enfermedad de depósitos de cadena livianas, las proteínas monoclonales pudieron ser identificadas por inmunofijación en el suero en $76 \%$ de los casos de la enfermedad y en la orina en $90 \%$, en $6 \%$ no se pudo hallar ninguna paraproteína y $32 \%$ fueron clasificados como idiopática.

El riñón se encuentra comprometido en $96 \%$ de los casos de cadenas livianas; la insuficiencia renal es la norma en la presentación y con una proteinuria superior a 3,5 g/día en más de $50 \%$ de los pacientes ${ }^{3,6}$. Las tres principales entidades resultado del depósito de cadenas livianas son: nefropatía por proteínas de Bence Jones (por lo general asociados con mieloma múltiple), enfermedad de depósitos de cadenas livianas (idiopática) y la amiloidosis $\mathrm{AL}^{7}$.

Como las cadenas livianas son normalmente filtradas por los glomérulos, reabsorbidas por endocitosis en los túbulos proximales y degradadas en las células tubulares, el riñón está generalmente involucrado en esta patología. Los glomérulos no sólo presentan prominentes nódulos intercapilares y esclerosis focal debido al compromiso mesangial, sino también las membranas basales, los túbulos, intersticio y las arterias están muy distorsionados y modificados por el depósito anómalo de cadenas livianas. A su vez, esta pérdida de proteínas en el intersticio conduce a fibrosis y atrofia tubular con la consiguiente disminución gradual y progresiva

Tabla 1. Clasificación de enfermedades asociados al depósito de cadenas livianas

1. Amiloidosis
AL amiloidosis
2. No amiloidosis
Mieloma múltiple
Enfermedad idiopática de cadenas livianas
Gammapatía monoclonal de significado incierto
Enfermedad idiopática de cadenas livianas y pesadas
Macroglobulinemia de Waldenström
Trastornos linfoproliferativos


de la función renal. Por microscopia óptica se pueden observar lesiones nodulares, patrón de glomerulonefritis membranoproliferativa tipo I, glomerulonefritis con semilunas, e incluso glomérulos normales (Tabla 2). La inmunofluorescencia es mandatoria, ya que el diagnóstico se basa en la documentación de una sola cadena liviana en la muestra de la biopsia ${ }^{3,7,8}$. La esclerosis nodular intercapilar también puede ser observada en la nefropatía diabética, amiloidosis y crioglobulinemia.

Los nódulos están conformados por colágeno tipo IV, laminina, fibronectina y tenascina ${ }^{9-11}$. Esta última es un componente del mesangio normal que tiende a acumularse en el centro de los nódulos mesangiales estimulados por el transforming growth factor $\beta$ (TGF- $\beta)^{12}$. La incubación de células mesangiales con las cadenas livianas induce la activación del platelet derived growth factor (PDGF) y su receptor, la producción de la proteína quimiotáctica del monocitos-1 (MCP1), y la expresión de Ki-67, un marcador de proliferación. El fenotipo resultante es similar a un fenotipo miofibroblástico, lo que sugiere que la exposición del mesangio a las cadenas livianas aumenta la producción de TGF- $\beta$, que a su vez inhibe la proliferación de la célula mesangial, y favorece el aumento y acumulación de proteínas de la matriz ${ }^{13,14}$.

En este caso, el mecanismo fisiopatológico responsable del edema se relaciona con la proteinuria severa, lo cual incrementó la sospecha en cuanto al origen glomerular de la misma. Posteriormente, fue confirmado mediante la realización del uroproteinograma electroforético con resultado positivo para albúmina y cadenas livianas policlonales. Con técnica de inmunofijación se caracterizaron las cadenas livianas como kappa (Kp), aunque sin evidencia de componente plasmático monoclonal. La biopsia renal confirmó el diagnóstico de glomerulopatía nodular secundaria a enfermedad por cadenas livianas kappa.

Por último, el manejo de la proteinuria es difícil de resolver. Cuando se trata de un paciente con una paraproteína y síndrome nefrótico, dos estrategias terapéuticas pueden ser delineadas: tratar de disminuir la producción de cadenas livianas con quimioterapia (en nuestro caso, esteroides más ciclofosfamida) y emplear la plasmaféresis para eliminar las cadenas de la circulación además de la hemodiálisis con filtros de alto "cutoff". A pesar de las nuevas estrategias terapéuticas disponibles, en

\section{Tabla 2. Alteraciones histológicas glomerulares} asociadas al depósito de cadenas livianas

Glomerulosclerosis nodular

Glomerulosclerosis focal

Glomerulosclerosis global

Glomerulonefritis proliferativa difusa

Glomerulonefritis membranoproliferativa tipo I

Glomerulonefritis crescéntica, por semilunas o extracapilar

Microaneurismas glomerurales intracapilares

este caso fueron utilizados los esteroides más ciclofosfamida debido a la frágil condición clínica del paciente. El tratamiento con quimioterapia, que es indiscutible en pacientes con mieloma, es controvertido cuando no hay una enfermedad maligna. No obstante la práctica general ha sido tratar con corticoides más melfalan, independientemente de la enfermedad hematológica acompañante, aunque los pacientes con mieloma reciben con más frecuencia ciclos de vincristina, doxorrubicina y dexametasona (VAD), que parece tener un efecto protector sobre la supervivencia del paciente ${ }^{15}$. Estudios recientes muestran la desaparición de los depósitos de cadenas ligeras en el riñón tras tratamiento con quimioterapia y trasplante de médula ósea ${ }^{16}$. El uso de nuevos agentes como el bortezomib han mostrado una rápida respuesta con un dramático descenso de los niveles de cadenas livianas en suero y orina en pequeñas series de casos $^{4}$. Sin embargo, la respuesta y la elección de la quimioterapia convencional, está limitada por los efectos adversos a nivel renal.

La plasmaféresis como estrategia aislada puede no ser útil en el manejo de la enfermedad por depósitos de cadenas livianas. Las cadenas livianas libres son moléculas de 25-50 kDa distribuidas por igual en los compartimentos intravascular y extravascular ${ }^{17}$. Sólo $20 \%$ de las cadenas livianas están disponibles para su eliminación. Por lo tanto, la quimioterapia es un complemento necesario. Como ha sugerido recientemente por Clark y Garg, la plasmaféresis debe ser considerada en esta población hasta disponer de mayor evidencia clínica $^{18}$.

En nuestro paciente, la plasmaféresis con reposición de albúmina resultó útil para la eliminación de paraproteínas y la mejoría en la albuminemia. 
Enfermedad por cadenas livianas - $\mathrm{H}$. Trimarchi et al

Se constató una mejoría en la hemodinamia renal y en la diuresis, pero la proteinuria alcanzó niveles excepcionalmente elevados (80 g/día) lo que podría haber contribuido con el desarrollo de MICS y el deterioro progresivo de la función renal. Creemos que la plasmaféresis podría haber disminuido el depósito de cadenas livianas en el glomérulo de haber sido iniciada precozmente ${ }^{19}$. La hemodiálisis diaria (usando filtros de alto "cutoff", como por ejemplo, el Gambro HCO1100, para la extracción de cadenas livianas) con ultrafiltración fue indicada con varios propósitos a pesar de niveles de creatinina y clearance normales: alcanzar gradualmente el peso seco, disminuir la morbilidad y mejorar su estado nutricional ${ }^{20}$. Esto también remarca el hecho que bajo ciertas circunstancias la creatinina sérica no es un marcador confiable de función renal y que la hemodiálisis, con ultrafiltración puede resultar útil para mejorar la malnutrición y la masa muscular secundaria al MICS, aún con clearance de creatinina normales ${ }^{20}$. Hubiera sido imposible manejar volumétricamente a nuestro paciente, sin la hemodiálisis, a pesar de haber podido acelerar el deterioro de la función renal.

La inmunofluorescencia es clave para el diagnóstico. La detección de cadenas livianas en plasma y/u orina es un método específico para establecer el diagnóstico, aunque con sensibilidad variable. Casi todos los pacientes progresan a enfermedad renal terminal, y la recidiva de la enfermedad es muy frecuente luego del trasplante renal $^{8}$. El pronóstico de los pacientes con este diagnóstico suele ser ominoso. La sobrevida depende del depósito de cadenas livianas, en especial en el corazón, siendo al año de $90 \%, 70 \%$ a los 5 años, con una media de 46 meses y sólo de $31 \%$ a los 8 años del diagnóstico ${ }^{3,6}$. La sobrevida renal es de $67 \%$ al año y $37 \%$ a los 5 años ${ }^{21}$. La enfermedad renal por cadenas livianas kappa cursa en apariencia con un mejor pronóstico en cuanto a la sobrevida que lambda ${ }^{5}$. El autotrasplante de células madres puede ser una opción terapéutica válida ya que induce la remisión hematológica en una proporción considerable de pacientes seleccionados. El trasplante renal no debe ser indicado a menos que exista una remisión hematológica completa ${ }^{8}$.

De acuerdo a lo expresado en este trabajo, la ECL debe ser considerada por los internistas dentro del diagnóstico diferencial en un paciente adulto con proteinuria de causa no aclarada.

\section{Referencias}

1. Randall RE, Williamson WC Jr, Mullinax F, Tung MY, Still WJ. Manifestations of systemic light chain deposition. Am J Med 1976: 60: 293-9 (Review).

2. Lin J, Markowitz GS, Valeri AM, Kambham N, Sherman WH, Appel GB, et al. Renal monoclonal immunoglobulin deposition disease: the disease spectrum. J Am Soc Nephrol 2001; 12: 1482-92.

3. Pozzi C, D’Amico M, Fogazzi GB, Curioni S, Ferrario F, Pasquali S, et al. Light chain deposition disease with renal involvement: clinical characteristics and prognostic factors. Am J Kidney Dis 2003; 42: 1154-63.

4. Jiménez-Zepeda VH. Light chain deposition disease: novel biological insights and treatment advances. Int J Lab Hematol 2012; 34: 347-55.

5. Shustik C, Bergsagel DE, Pruzanski W. Kappa and lambda light chain disease: Survival rates and clinical manifestations. Blood 1976; 48: 41-51.

6. Nasr SH, Valeri AM, Cornell LD, Fidler ME, Sethi S, D'Agati VD, et al. Renal monoclonal immunoglobulin deposition disease: a report of 64 patients from a single institution. Clin J Am Soc Nephrol 2012; 7: 231-9.

7. Cohen AH. The kidney in plasma cell dyscrasias: BenceJones cast nephropathy and light chain deposition disease. Am J Kidney Dis 1998; 32: 529-32.

8. Salant DJ, Sanchorawala V, D’Agati VD. A case of atypical light chain deposition disease-diagnosis and treatment. Clin J Am Soc Nephrol 2007; 2: 858-67.

9. Khamlichi AA, Aucouturier P, Preud'homme JL, Cogné M. Structure of abnormal heavy chains in human heavychain-deposition disease. Eur J Biochem 1995; 229: 5460.

10. Bruneval P, Foidart JM, Nochy D, Camilleri JP, Bariety J. Glomerular matrix proteins in nodular glomerulosclerosis in association with light chain deposition disease and diabetes mellitus. Hum Pathol 1985; 16 : 477-84.

11. Truong LD, Pindur J, Barrios R, D’Agati V, Lechago J, Suki WN, et al. Tenascin is an important component of the glomerular extracellular matrix in normal and pathologic conditions. Kidney Int 1994; 45: 201-10.

12. Ronco P, Plaisier E, Mougenot B, Aucouturier P. Immunoglobulin light (heavy)-chain deposition disease: from molecular medicine to pathophysiology-driven therapy. Clin J Am Soc Nephrol 2006; 1: 1342-50.

13. Zhu L, Herrera GA, Murphy-Ullrich JE, Huang ZQ, Sanders PW. Pathogenesis of glomerulosclerosis in light chain deposition disease. Role for transforming growth factor-beta. Am J Pathol 1995; 147: 375-85.

14. Russell WJ, Cardelli J, Harris E, Baier RJ, Herrera GA. 
Monoclonal light chain-mesangial cell interactions: Early signalling events and subsequent pathologic effects. Lab invest 2001; 81: 689-703.

15. Royer B, Arnulf B, Martínez F, Roy L, Flageul B, Etienne I, et al. High dose chemotherapy in light chain or light and heavy chain deposition disease. Kidney Int 2004; 65: 642-8.

16. Firkin F, Hill PA, Dwyer K, Gock H. Reversal of dialysisdependent renal failure in light-chain deposition disease by autologous peripheral blood stem cell transplantation. Am J Kidney Dis 2004; 44: 551-5.

17. Cserti C, Haspel R, Stowell C, Dzik W. Light-chain removal by plasmapheresis in myeloma-asscociated renal failure. Transfusion 2007; 47: 511-4.
18. Clark WF, Garg AX. Plasma exchange for myeloma kidney: cast(s) away? Kidney Int 2008; 73: 1211-3.

19. McLeod BC, Viernes AL, Sassetti RJ. Serum-free light chain analysis by crossed immunoelectrophoresis: Correlation with plasmapheresis in light chain disease nephropathy. Am J Hematol 1983; 15: 75-88.

20. Young P, Lombi F, Finn BC, Forrester M, CampoloGirard V, Pomeranz V, et al. "Síndrome complejo de malnutrición e inflamación” en hemodiálisis crónica. Medicina (B. Aires) 2011; 71: 66-72.

21. Heilman RL, Velosa JA, Holley KE, Offord KP, Kyle RA. Long-term follow-up and response to chemotherapy in patients with light-chain deposition disease. Am J Kidney Dis 1992; 20: 34-41. 